\title{
Perdas fermentativas, composição química, estabilidade aeróbia e digestibilidade aparente de silagem de cana-de-açúcar com aditivos químico e microbiano
}

\author{
Geraldo Balieiro Neto(1), Evaldo Ferrari Junior( ${ }^{(2)}$, José Ramos Nogueira(1), Rosana Possenti( ${ }^{(2)}$, \\ Valdinei Tadeu Paulino(2) e Mauro Sartori Bueno(2)
}

(1)Agência Paulista de Tecnologia dos Agronegócios, Avenida Bandeirantes, no 2.419, Bairro Vila Virgínia, CEP 14030-670 Ribeirão Preto, SP. E-mail: geraldobalieiro@apta.sp.gov.br, jr@apta.sp.gov.br (2)Instituto de Zootecnia de Nova Odessa, Rua Heitor Penteado, no 56, CEP 13460-000 Nova Odessa, SP. E-mail: ferrari@iz.sp.gov.br, possenti@iz.sp.gov.br, paulino@iz.sp.gov.br

Resumo - O objetivo deste trabalho foi avaliar a influência da adição de cal virgem e Lactobacillus buchneri em perdas fermentativas, valor nutritivo, estabilidade aeróbia e digestibilidade aparente da silagem de cana-de-açúcar (Saccharum officinarum). O primeiro experimento avaliou perdas fermentativas, $\mathrm{pH}$ e temperatura, composição química e digestibilidade in vitro da matéria seca de silagens de cana-de-açúcar, com adição ou sem adição de cal ou de inoculante bacteriano (L. buchneri); o segundo avaliou o consumo de matéria seca e a digestibilidade aparente da cana-de-açúcar ensilada com os mesmos aditivos para cordeiros. Os aditivos não reduziram as perdas na ensilagem, e silagens com cal apresentaram maiores perdas por efluentes. O consumo de matéria seca da silagem com inoculante foi inferior ao da silagem com cal ou ao da cana-de-açúcar in natura. A digestibilidade aparente da matéria seca da silagem com cal foi inferior à da cana-de-açúcar in natura e à da silagem com inoculante. A digestibilidade aparente do extrato etéreo das silagens com cal foi superior à da cana-de-açúcar in natura. Os valores de nutrientes digestíveis totais da cana-de-açúcar in natura ou ensilada com inoculante ou cal foram de 61,2, 54,1 e 51,7\%, respectivamente. Independentemente do aditivo, a ensilagem da cana-de-açúcar resulta em perda de nutrientes e redução de digestibilidade.

Termos para indexação: Lactobacillus buchneri, Saccharum officinarum, consumo de matéria seca, NDT, óxido de cálcio, valor nutritivo.

\section{Fermentation losses, chemical composition, aerobic stability and apparent digestibility of sugarcane ensiling with chemical and microbial additives}

\begin{abstract}
The objective of this work was to evaluate the influence of the addition of whitewash $(\mathrm{CaO})$ and Lactobacillus buchneri in fermentation losses, nutritional value, aerobic stability and apparent digestibility of sugarcane (Saccharum officinarum) silages. A first experiment evaluated fermentation losses, $\mathrm{pH}$ and temperature values, chemical composition and in vitro dry matter digestibility of sugarcane silages with or without bacterial inoculants (L. buchneri) or CaO. A second experiment evaluated intake and apparent digestibility of sugarcane silage with the same additives to sheep. The additives did not reduce silage losses, and silages with $\mathrm{CaO}$ presented greater effluent losses. The intake of silage with inoculant was lower than of silage with $\mathrm{CaO}$ and in natura sugarcane. Dry matter apparent digestibility of $\mathrm{CaO}$ silage was lower than that of in natura sugarcane and of silage with inoculant. Greater values were observed in ether extract for silage treated with $\mathrm{CaO}$ when compared to in natura sugarcane. Total digestible nutrients values of in natura sugarcane and of silage with inoculant or $\mathrm{CaO}$ were $61.2,54.1$, and $51.7 \%$, respectively. Regardless of the additive, sugarcane ensilage results in nutrient loss and in reduced digestibility.
\end{abstract}

Index terms: Lactobacillus buchneri, Saccharum officinarum, dry matter intake, TDN, calcium oxide, nutritive value.

\section{Introdução}

O alto teor de açúcares solúveis presente na canade-açúcar confere a essa planta a maior produção de nutrientes digestíveis totais por área $\left(15 \mathrm{a} 20 \mathrm{Mg} \mathrm{ha}^{-1}\right.$ em um único corte), o que a torna uma boa alternativa para aumento da receita líquida por hectare na pecuária leiteira (Magalhães et al., 2004) ou de corte (Nussio et al., 2003).
A prática de ensilagem elimina a necessidade do corte diário e representa uma solução operacional para o aproveitamento do potencial produtivo da canade-açúcar em larga escala. Entretanto, o alto teor de carboidratos solúveis promove rápida proliferação de leveduras e produção de etanol e gás carbônico, resulta em perda de nutrientes solúveis e, consequentemente, na redução no valor nutritivo, o que normalmente inviabiliza a ensilagem (Kung Junior \& Stanley, 
1982). A predominância da fermentação alcoólica em silagens de cana-de-açúcar reportada por Preston et al. (1976) foi confirmada em trabalhos recentes (Pedroso et al., 2005; Freitas et al., 2006), que relataram perdas de matéria seca (MS) da ordem de 30\%. Aditivos químicos e biológicos têm sido estudados na tentativa de viabilizar a ensilagem da cana-de-açúcar. A cal virgem e inoculantes contendo Lactobacillus buchneri são os principais aditivos propostos, mas os resultados são controversos.

Driehuis et al. (1999) demonstraram que a adição de inoculantes contendo $L$. buchneri melhora a estabilidade aeróbia de silagens de milho por meio da redução do crescimento e da sobrevivência de leveduras. Pedroso et al. (2007) demonstraram que o inoculante contendo L. buchneri inibe a produção de álcool, reduz a proliferação de fungos e leveduras e evita perdas por fermentações indesejáveis em silagens de cana-de-açúcar. Por outro lado, Freitas et al. (2006) não observaram nenhuma melhoria na composição química ou no perfil de fermentação, ou redução na perda de MS em silagens de cana-de-açúcar com inoculação de L. buchneri em relação à silagem sem aditivo. Da mesma forma, Santos et al. (2009) não encontraram alterações no processo fermentativo de silagens de cana-de-açúcar contendo L. buchneri em comparação com silagens sem aditivo. Balieiro Neto et al. (2007) observaram que a adição de cal virgem reduz os teores de fibra insolúvel em detergente neutro $(\mathrm{FDN})$ e promove maior digestibilidade in vitro da silagem. Contudo, são escassos os resultados sobre consumo de alimento e o ganho de peso ou conversão alimentar de animais que recebem o volumoso tratado.

A maioria dos estudos da silagem de cana-deaçúcar deteve-se no efeito de aditivos sobre o processo fermentativo e a composição química da silagem produzida. No entanto, a eventual eficiência do aditivo em reduzir perdas e melhorar a qualidade da silagem não pressupõe a viabilidade da ensilagem. Para verificar a viabilidade, é necessário avaliar a produção de energia digestível da cana-de-açúcar quando utilizada na forma de silagem ou in natura e, portanto, considerar quantidade e qualidade concomitantemente.

Este trabalho teve como objetivo avaliar a influência da adição de cal virgem e de L. buchneri em perdas fermentativas, valor nutritivo, estabilidade aeróbia e digestibilidade aparente da silagem de cana-de-açúcar.

\section{Material e Métodos}

O experimento foi conduzido no Pólo Regional Centro-Leste da Agência Paulista de Pesquisa dos Agronegócios em Ribeirão Preto, SP, e no Instituto de Zootecnia em Nova Odessa, SP. A cultivar de cana-deaçúcar utilizada foi a IAC 86-2480, proveniente de corte realizado em soqueira com 12 meses (segundo corte).

A forragem de cana-de-açúcar foi colhida por ensiladora regulada para corte de partículas de $2 \mathrm{~cm}$ de comprimento. A forragem picada recebeu a adição de $0,5 \%$ de cal virgem na matéria fresca ou a inoculação de L. buchneri, na dose de $10^{6} \mathrm{UFC} \mathrm{g}^{-1}$ de matéria fresca. A cal virgem foi utilizada misturada em pó micropulverizado, com a seguinte composição química percentual: $0,50 \%$ de $\mathrm{Al}_{2} \mathrm{O}_{3}, 1,26 \%$ de $\mathrm{CO}_{2}, 94,59 \%$ de $\mathrm{CaO}, 0,22 \%$ de $\mathrm{Fe}_{2} \mathrm{O}_{3}, 0,36 \%$ de $\mathrm{MgO}, 0,09 \%$ de $\mathrm{P}$, $0,09 \%$ de $\mathrm{S}$ e $1,80 \%$ de $\mathrm{SiO}_{2}$.

Foram avaliadas a perda de matéria seca e as perdas por efluentes e gás das silagens de cana-de-açúcar sem aditivo (controle), de cana-de-açúcar com $0,5 \%$ de cal virgem e de cana-de-açúcar com L. buchneri. Como silos experimentais, foram utilizados cinco baldes de plástico com capacidade de $5 \mathrm{~L}$, que continham tampas com válvulas de Bunsen para o escape de gases. No fundo de cada silo, foram colocados $2 \mathrm{~kg}$ de areia, separados da forragem por uma tela de plástico, para a quantificação de efluentes. A forragem foi compactada nos silos com o auxílio de soquetes de cimento, para que as silagens atingissem densidade de $600 \mathrm{~kg} \mathrm{~m}^{-3}$ (Ruppel et al., 1995). Após a compactação, os silos foram vedados com fita adesiva, pesados e armazenados à sombra.

A perda total de matéria seca durante o período de ensilagem (fase anaeróbia) foi calculada pela diferença entre o peso da MS inicial e final nos silos (Jobim et al., 2007). A perda por gases (G) no processo de ensilagem foi calculada com base na pesagem dos silos no fechamento e na abertura em relação à massa de forragem armazenada, descontada a tara do silo (Jobim et al., 2007). A quantidade de efluentes (E) foi estimada pelo acréscimo na massa do conjunto balde, areia e tela, pela equação: $E=[100(\mathrm{Pab}-\mathrm{Pen})] /(\mathrm{MVfe})$, em que E é a produção de efluente $\left(\mathrm{kg} \mathrm{Mg}^{-1}\right.$ de massa de matéria verde); Pab é a massa $(\mathrm{kg})$ do conjunto (balde+areia+tela) por ocasião da abertura; Pen é a massa $(\mathrm{kg})$ do conjunto (balde+areia+tela) por ocasião da ensilagem; MVfe é a massa de matéria verde de forragem ensilada $(\mathrm{kg})$. 
Para avaliação da estabilidade aeróbia, o conteúdo de cada silo foi homogeneizado e $3 \mathrm{~kg}$ de silagem foram colocados em baldes, sem compactação, e transferidos para câmara climática a $25 \pm 1{ }^{\circ} \mathrm{C}$. As temperaturas das silagens foram verificadas duas vezes ao dia, durante nove dias, com uso de termômetro inserido no centro da massa de forragem, conforme Bernardes et al. (2007). A avaliação da estabilidade aeróbia foi calculada com os parâmetros propostos por O'Kiely et al. (1999), apresentados em número de dias para elevação da temperatura da silagem em $2^{\circ} \mathrm{C}$ em relação à temperatura ambiente, número de dias para atingir a temperatura máxima, temperatura máxima e soma das médias diárias de temperatura nas silagens expostas ao ar de zero a nove dias. $\mathrm{O} \mathrm{pH}$ das silagens, do dia da abertura ao nono dia de exposição aeróbia, foi determinado segundo o procedimento descrito por Kung Junior et al. (1984).

A recuperação de matéria seca (RMS) durante os nove dias de exposição ao ar foi obtida de acordo com Bernardes et al. (2007), com uso da seguinte equação: RMS = 100[(MFf x MSf)/(MFi x MSi)], em que RMS é o índice de recuperação de matéria seca; MFf é a massa de forragem final; MSf é o teor de MS final; MFi é a massa de forragem inicial; MSi é o teor de MS inicial. Os resultados foram apresentados em perda de matéria seca.

Foram coletadas amostras das forragens logo após a aplicação dos aditivos, no momento da abertura dos silos (após 84 dias de armazenamento) e três, seis e nove dias após a abertura. As amostras foram pesadas e secas em estufa com circulação forçada de ar a $65^{\circ} \mathrm{C}$ por 72 horas, para obtenção do teor de matéria seca (MS); posteriormente, foram moídas para a determinação dos teores de proteína bruta $(\mathrm{PB})$, extrato etéreo (EE) e matéria mineral (MM) de acordo com Silva \& Queiroz (2002). Foram determinadas a fibra insolúvel em detergente neutro (FDN) e fibra insolúvel em detergente ácido (FDA), conforme Van Soest et al. (1991). Os carboidratos não fibrosos (CNF) e carboidratos totais (CHOT) foram obtidos pelas equações: $\mathrm{CNF}=100-(\mathrm{FDN}+$ $\mathrm{PB}+\mathrm{EE}+\mathrm{MM})$ e $\mathrm{CHOT}=100-(\mathrm{PB}+\mathrm{EE}+\mathrm{MM})$. A digestibilidade in vitro da matéria seca (DIVMS) e da matéria seca digestível verdadeira (DIVMS verdadeira) foram determinadas de acordo com Silva \& Queiroz (2002).
Foram determinadas a digestibilidade in vivo da silagem com L. buchneri e da silagem com $0,5 \%$ de cal virgem. $\mathrm{O}$ ensaio de digestibilidade aparente foi realizado pelo método de coleta total de fezes. Foram utilizados 15 carneiros inteiros da raça Ille de France, com idade de oito a dez meses e peso vivo médio de $46,10 \pm 4,67 \mathrm{~kg}$, separados em cinco blocos, cada bloco formado por três animais com o mesmo peso vivo. Para que o baixo teor de PB não limitasse o consumo de matéria seca da cana-de-açúcar, além de sal mineral e água à vontade, todas as dietas foram suplementadas com $70 \mathrm{~g}$ de proteína digestível por meio do fornecimento de $150 \mathrm{~g}$ de farelo de soja com $46,4 \%$ de proteína digestível, o que supre a exigência de mantença dos animais (National Research Council, 1985). Cada tratamento foi fornecido para cinco carneiros, em gaiolas individuais com coletor de fezes. O período de adaptação e controle de consumo foi de 14 dias e o período de coleta foi de oito dias. No período de coleta, os animais receberam a quantidade de silagem determinada de acordo com o consumo voluntário e as sobras foram pesadas. As mesmas análises realizadas nas silagens e na cana-de-açúcar fresca foram realizadas nas sobras e nas fezes. Foram observadas as digestibilidades de MS (DIGMS); PB (DIGPB), EE (DIGEE), FDN (DIGFDN), FDA (DIGFDA), hemicelulose (DIGHEM), carboidratos não fibrosos (DIGCNF) e carboidratos totais (DIGCHOT). O cálculo dos nutrientes digestíveis totais (NDT) foi realizado por meio da seguinte equação: $\mathrm{NDT}=\mathrm{PB}$ digestível $+(2,25$ $\times$ EE digestível) + FDN digestível + CNF digestível (National Research Council, 2001).

$\mathrm{O}$ delineamento experimental utilizado nas avaliações de perdas fermentativas na ensilagem, de estabilidade aeróbia e de valor nutritivo foi o inteiramente casualizado, em esquema de parcelas subdivididas, em que as silagens (sem aditivo, com $0,5 \%$ de cal e com L. buchneri) corresponderam às parcelas e os tempos de avaliação (ensilagem, abertura e três, seis e nove dias após abertura), às subparcelas. $\mathrm{Na}$ avaliação do consumo de matéria seca, digestibilidade aparente e valor energético, foi utilizado o delineamento em blocos completos ao acaso, com três tratamentos e cinco repetições. Os dados foram submetidos à análise de variância pelo procedimento PROC MIXED com uso do SAS (SAS Institute, 2003), e as médias foram comparadas pelo teste de Tukey, a 5\% de probabilidade. 


\section{Resultados e Discussão}

A adição de cal virgem ou inoculante não reduziu as perdas de MS durante a ensilagem (Tabela 1). A perda de MS de 19,5\% observada neste trabalho, na ensilagem sem aditivo, foi próxima à perda de $18,3 \%$ encontrada por Pedroso et al. (2007) e inferior à perda de $31 \%$ encontrada por Freitas et al. (2006). Freitas et al. (2006) também constataram que o inoculante contendo L. buchneri não foi eficiente para conter perdas de MS na ensilagem. Santos et al. (2009), por sua vez, observaram que não houve alteração no processo fermentativo em silagens de cana-de-açúcar contendo L. buchneri em comparação com a silagem sem inoculante.

Os valores de perda de MS por gás obtidos neste trabalho, de 9,4\% para silagens sem inoculante e 9,2\% para silagens com inoculante, foram próximos aos valores de 10,3 e $8,9 \%$ obtidos por Pedroso et al. (2007). Não houve diferença significativa entre os tratamentos (Tabela 1). Schmidt et al. (2007) também não observaram diferença entre a produção de etanol e de ácidos orgânicos em silagens com inoculante contendo L. buchneri e sem inoculante.

A adição de cal virgem aumentou a perda por efluentes na ensilagem, que resulta em perda de nutrientes solúveis (Tabela 1). A cal aparentemente altera a integridade estrutural da célula e afeta a sua pressão osmótica e capacidade de reter água, o que causa ruptura da membrana e vazamento de conteúdo celular (Woolford, 1978), que levaria a maior perda de nutrientes solúveis por efluentes. Esse efeito explica a diferença entre os valores da produção de gás entre silagens com cal e silagens sem cal, pois a maior perda de carboidratos solúveis por efluentes em silagens com cal reduz a sua disponibilidade para a produção de gás. A produção de efluente em silagens com inoculante foi inferior à da silagem com cal e não se diferenciou da produção da silagem sem aditivo (Tabela 1), o que está em desacordo com Pedroso et al. (2007), que observaram maior produção de efluentes em silagem com inoculante em comparação à silagem sem aditivo.

A cal virgem e o inoculante contendo L. buchneri reduziram a perda de MS após abertura do silo (Tabela 1) e aumentaram a estabilidade aeróbia das silagens, em comparação com a silagem sem aditivo (Tabelas 2 e 3).

Houve acréscimo no número de dias necessários para aumento de $2^{\circ} \mathrm{C}$ na temperatura das silagens, nos tratamentos com aditivo (Tabela 2). $\mathrm{O}$ aumento da temperatura é resultado do balanço entre a taxa de calor produzida pela atividade microbiana e as perdas de calor por condução, radiação, evaporação e convecção, e está diretamente relacionado à oxidação da matéria seca, que provoca perdas na forma de dióxido de carbono (Hill \& Leaver, 2002).

Os principais microrganismos relacionados à deterioração da silagem exposta ao ar são os fungos, com destaque para as leveduras, e as bactérias do gênero Bacillus (Woolford, 1990). As bactérias, leveduras, bolores e fungos podem ficar dormentes dentro do silo até que ele seja aberto e o ar entre novamente na massa ensilada. Esses microrganismos utilizam substratos derivados diretamente da forragem, ou derivados indiretamente da fermentação, e alteram as características qualitativas do material, provocando perdas de nutrientes do material na desensilagem. A bactéria heterofermentativa $L$. buchneri tem apresentado eficiência no controle do desenvolvimento de leveduras, por promover a redução da sobrevivência desses microrganismos após exposição ao ar e o aumento da estabilidade aeróbia das silagens (Driehuis et al., 1999; Elferink et al., 2001). O aumento da estabilidade aeróbia da silagem de cana-de-açúcar com inoculação de L. buchneri corrobora os resultados obtidos por Queiroz et al. (2008). De acordo com esses autores, a maior estabilidade de silagens contendo L. buchneri deve-se à presença de ácido acético, que inibe o desenvolvimento microbiano durante o período de exposição da silagem ao ar.

Tabela 1. Perdas fermentativas de silagens de cana-de-açúcar tratadas com cal virgem ou Lactobacillus buchneri ${ }^{(1)}$.

\begin{tabular}{lccc}
\hline Tratamento & & Fase anaeróbia & \multicolumn{1}{c}{ Fase aeróbia } \\
\cline { 2 - 4 } & Efluentes $\left(\mathrm{kg} \mathrm{Mg}^{-1}\right)$ & Gases $(\% \mathrm{MS})$ & Perda $(\% \mathrm{MS})$ \\
\hline Sem aditivo & $10,81 \mathrm{~b}$ & $9,43 \mathrm{a}$ & $19,51 \mathrm{a}$ \\
$0,5 \%$ cal & $43,02 \mathrm{a}$ & $7,82 \mathrm{a}$ & $19,85 \mathrm{a}$ \\
L. buchneri & $12,31 \mathrm{~b}$ & $9,16 \mathrm{a}$ & $23,50 \mathrm{a}$ \\
\hline $\mathrm{EP}^{(2)}$ & 10,78 & 0,91 & $14,73 \mathrm{~b}$ \\
\hline
\end{tabular}

${ }^{(1)}$ Médias seguidas por letras iguais, nas colunas, não diferem entre si pelo teste de Tukey, a 5\% de probabilidade. ${ }^{(2)}$ Erro-padrão da média. 
Houve interação significativa $(\mathrm{p}<0,0001)$ entre aditivo e tempo após a abertura do silo sobre os valores de $\mathrm{pH}$ das silagens (Tabela 3 ). O alto teor de carboidratos solúveis e o baixo teor de proteína bruta inibem, na cana-de-açúcar, a resistência à queda de $\mathrm{pH}$ (Balieiro Neto et al., 2009), mas, após a abertura do silo, o pH se eleva de forma diferente entre os tratamentos, com o passar do tempo (Tabela 3). Na silagem sem aditivo, o aumento no valor de $\mathrm{pH}$ ocorreu no terceiro dia, enquanto silagens com aditivo sofreram alteração no quarto dia após a abertura do silo (Tabela 3). O maior tempo necessário de exposição ao ar para aumento no valor de $\mathrm{pH}$ em silagens com aditivo acompanhou o avanço no número de dias para elevação da temperatura em $2^{\circ} \mathrm{C}$ e a menor perda de matéria seca na fase aeróbia desses tratamentos. Segundo Pahlow et al. (2003), o valor de pH se eleva após a abertura do silo, quando ácidos orgânicos que preservam a silagem são consumidos por microrganismos. $\mathrm{O} \mathrm{pH}$ e a umidade são os principais fatores de supressão do crescimento clostridiano, e o desenvolvimento dos clostrídios é restrito quando a forragem apresenta $\mathrm{pH}$ inferior a 4,2 (Leibensperger \& Pitt, 1987). Os valores elevados de $\mathrm{pH}$ na silagem com cal virgem não a classificam, no entanto, como de baixa qualidade, haja vista a natureza fortemente alcalina do produto adicionado.

Os teores de MS e de PB da cana-de-açúcar na ensilagem apresentados na Tabela 4 foram próximos aos valores de 28,6 e 2,6\% observados por Freitas et al. (2006). Os teores de MS nas silagens sem aditivo e contendo L. buchneri por ocasião da abertura (Tabela 4) foram próximos aos encontrados por Pedroso et al. (2007) e ligeiramente superiores aos encontrados por Freitas et al. (2006). $\mathrm{O}$ processo que leva à perda de carboidratos solúveis na forma de gases durante a fermentação também resulta em produção de água, o que diminui o teor de MS, de forma que o menor teor de MS no momento da abertura dos silos

Tabela 2. Variáveis de temperatura associadas à estabilidade aeróbia de silagens de cana-de-açúcar ${ }^{(1)}$.

\begin{tabular}{lcccc}
\hline Variáveis & & & \\
\hline St & Sem aditivo & Cal virgem & L. buchneri & $\mathrm{EP}^{(3)}$ \\
\hline $\mathrm{t}^{\circ} \mathrm{C}$ máx. & 238 & 250 & 251 & 5,72 \\
Dias $\mathrm{t}^{\circ} \mathrm{C}$ máx. & 34,8 & 35,0 & 39,0 & 2,58 \\
Dias $\mathrm{t}^{\circ} \mathrm{C}>2^{\circ} \mathrm{C}$ & 3,2 & 3,0 & 3,2 & 0,38 \\
\hline
\end{tabular}

${ }^{(1)}$ Médias seguidas por letras iguais, nas linhas, não diferem entre si pelo teste de Tukey, a 5\% de probabilidade. ${ }^{(2)} \mathrm{St}{ }^{\circ} \mathrm{C}$ 0-9 dias, soma da média diária de temperatura de 0 a 9 dias de exposição ao ambiente; $\mathrm{t}^{\circ} \mathrm{C}$ máx., temperatura máxima atingida pela massa; Dias $\mathrm{t}^{\circ} \mathrm{C}$ máx., número de dias para atingir a temperatura máxima; Dias $\mathrm{t}^{\circ} \mathrm{C}>2^{\circ} \mathrm{C}$, número de dias para elevação da temperatura em $2{ }^{\circ} \mathrm{C}$. ${ }^{(3)}$ Erro-padrão da média. deve-se à produção de água do metabolismo resultante do processo fermentativo. Durante a aerobiose, do momento da abertura até o terceiro dia após a abertura, todas as silagens sofreram aumento no teor de MS (Tabela 4). No sexto dia de exposição ao ar, enquanto as silagens com aditivo perderam água com incrementos no teor de MS, as silagens sem aditivo mantiveram o teor de MS em razão da maior atividade metabólica com produção de água.

$\mathrm{O}$ aumento na concentração de PB após a ensilagem provavelmente ocorreu em função das perdas de carboidratos solúveis por efluentes e produção de gás. Dessa forma, a maior concentração de PB na silagem sem aditivo, em relação à silagem com inoculante bacteriano nove dias após abertura dos silos, indica maior perda de carboidratos solúveis.

Houve aumento dos teores de FDN e redução dos teores de carboidratos não fibrosos (CNF) durante as fases anaeróbia e aeróbia (Tabela 4). Houve interação significativa $(p<0,001)$ entre tempo e aditivo sobre o percentual de carboidratos não fibrosos (CNF). A concentração de CNF foi maior na silagem com inoculante que na silagem sem aditivo. Schmidt et al. (2007) também observaram elevação nos teores de FDN e redução no teor de carboidratos solúveis após a ensilagem em relação à cana-de-açúcar in natura. Esse efeito deve-se à perda de carboidratos solúveis pela formação de efluentes e produção de gás durante o processo fermentativo, o que resulta em aumento proporcional da fração menos fermentável e insolúvel em água, como os constituintes da parede celular.

A maior concentração de $\mathrm{PB}$ da silagem sem aditivo, quando comparada à da silagem com inoculante no nono dia após abertura, e o maior teor de FDN, quando comparado ao da silagem com cal virgem no sexto dia

Tabela 3. Valores de $\mathrm{pH}$ em diferentes tempos após a abertura de silagens de cana-de-açúcar com cal virgem e Lactobacillus buchneri ${ }^{(1)}$.

\begin{tabular}{cccc}
\hline Dias após abertura & Sem aditivo & $0,5 \% \mathrm{cal}$ & L. buchneri \\
\hline 1 & $3,66 \mathrm{Ca}$ & $4,04 \mathrm{Da}$ & $3,60 \mathrm{Ba}$ \\
2 & $3,67 \mathrm{Ca}$ & $4,08 \mathrm{Da}$ & $3,70 \mathrm{Ba}$ \\
3 & $3,72 \mathrm{Ca}$ & $4,08 \mathrm{Da}$ & $3,82 \mathrm{Ba}$ \\
4 & $4,76 \mathrm{Ba}$ & $4,31 \mathrm{Da}$ & $4,26 \mathrm{Ba}$ \\
5 & $5,45 \mathrm{Ba}$ & $5,22 \mathrm{Ca}$ & $5,02 \mathrm{Aa}$ \\
6 & $5,63 \mathrm{Bb}$ & $6,95 \mathrm{Ba}$ & $5,24 \mathrm{Ab}$ \\
7 & $5,72 \mathrm{Ab}$ & $7,93 \mathrm{Aa}$ & $5,26 \mathrm{Ab}$ \\
8 & $5,74 \mathrm{Ab}$ & $8,39 \mathrm{Aa}$ & $5,51 \mathrm{Ab}$ \\
9 & $4,97 \mathrm{ABb}$ & $6,86 \mathrm{Aba}$ & $5,29 \mathrm{Ab}$ \\
\hline
\end{tabular}

(1)Médias seguidas por letras iguais, maiúsculas nas colunas e minúsculas nas linhas, não diferem entre si pelo teste de Tukey, a 5\% de probabilidade. 
após a abertura dos silos (Tabela 4), são coerentes com a maior perda de MS da silagem sem aditivo durante a fase aeróbia.

$\mathrm{O}$ teor de FDN da forragem tratada com cal virgem foi menor que o da silagem sem aditivo e o da silagem contendo inoculante microbiano antes da ensilagem e na abertura do silo, respectivamente (Tabela 4). Van Soest (1994) menciona que o álcali (OH) ataca grupos fenólicos e pode romper ligações do tipo éster entre o ácido urônico da hemicelulose. Além disso, o rompimento das ligações intermoleculares das pontes de hidrogênio, que ligam moléculas de celulose, pode ocasionar expansão da celulose (Jackson, 1977).
Balieiro Neto et al. (2007) observaram que a cal virgem reduziu os teores de FDN da silagem de canade-açúcar.

A diferença entre teores de CNF nas silagens controle e com inoculação $(38 \times 42 \%)$ resultou em valores de 64 e $67 \%$ de DIVMS, respectivamente. A ensilagem reduziu a DIVMS e DIVMS verdadeira, e a silagem com cal apresentou DIVMS verdadeira superior à da silagem controle ou à da silagem com inoculante microbiano (Tabela 4). Quando comparada à silagem controle, a maior DIVMS verdadeira em silagens com cal condiz com os menores teores de FDN nela presentes por ocasião da ensilagem e aos três dias após a abertura

Tabela 4. Composição químico-bromatológica, digestibilidade in vitro e digestibilidade in vitro verdadeira de silagens de cana-de-açúcar sem aditivo, com cal virgem e com Lactobacillus buchneri antes e depois da ensilagem e após três, seis e nove dias de exposição ao $\operatorname{ar}^{(1)}$.

\begin{tabular}{|c|c|c|c|c|c|c|}
\hline \multirow[t]{2}{*}{ Tratamentos } & \multicolumn{2}{|c|}{ Fase anaeróbia } & \multicolumn{3}{|c|}{ Fase aeróbia } & \multirow[t]{2}{*}{ Média } \\
\hline & Antes & Depois & 3 dias & 6 dias & 9 dias & \\
\hline & \multicolumn{6}{|c|}{ Matéria seca (\%) } \\
\hline Sem aditivo & $26,91 b c$ & $23,82 \mathrm{c}$ & $34,05 \mathrm{a}$ & $35,92 \mathrm{Ba}$ & $29,97 b$ & 30,14 \\
\hline $0,5 \%$ cal & $27,32 b$ & $24,76 b$ & $36,77 \mathrm{a}$ & $39,76 \mathrm{ABa}$ & $27,92 b$ & 31,31 \\
\hline L. buchneri & $27,86 \mathrm{c}$ & $23,35 \mathrm{c}$ & $35,32 \mathrm{~b}$ & $45,06 \mathrm{Aa}$ & $27,33 \mathrm{c}$ & 31,78 \\
\hline \multirow[t]{2}{*}{ Média } & 27,36 & 23,98 & 35,38 & 40,25 & 28,41 & \\
\hline & \multicolumn{6}{|c|}{ Proteína bruta (\% MS) } \\
\hline Sem aditivo & $3,00 \mathrm{c}$ & $3,19 b c$ & $3,89 \mathrm{ab}$ & $3,78 \mathrm{ab}$ & $4,27 \mathrm{Aa}$ & 3,62 \\
\hline $0,5 \%$ cal & $2,91 \mathrm{~b}$ & $3,26 \mathrm{ab}$ & $3,66 \mathrm{a}$ & $3,48 \mathrm{ab}$ & $3,86 \mathrm{ABa}$ & 3,43 \\
\hline L. buchneri & $2,59 \mathrm{~b}$ & $3,34 \mathrm{a}$ & $3,76 \mathrm{a}$ & $3,74 \mathrm{a}$ & $3,36 \mathrm{Ba}$ & 3,36 \\
\hline \multirow[t]{2}{*}{ Média } & 2,83 & 3,26 & 3,77 & 3,67 & 3,83 & \\
\hline & \multicolumn{6}{|c|}{ Fibra em detergente neutro (\% MS) } \\
\hline Sem aditivo & $55,48 \mathrm{Ac}$ & $63,33 \mathrm{ABb}$ & $65,97 \mathrm{~b}$ & $70,97 \mathrm{Aa}$ & $70,47 \mathrm{a}$ & 65,24 \\
\hline $0,5 \% \mathrm{cal}$ & $51,33 \mathrm{Bc}$ & $60,39 \mathrm{Bb}$ & $63,02 b$ & $66,62 \mathrm{Ba}$ & $69,91 \mathrm{a}$ & 62,25 \\
\hline L. buchneri & $52,00 \mathrm{ABd}$ & $66,81 \mathrm{Acb}$ & $65,59 \mathrm{c}$ & $69,95 \mathrm{ABab}$ & $72,54 \mathrm{a}$ & 65,38 \\
\hline \multirow[t]{2}{*}{ Média } & 52,94 & 63,51 & 64,86 & 69,18 & 70,97 & \\
\hline & \multicolumn{6}{|c|}{ Fibra em detergente ácido (\% MS) } \\
\hline Sem aditivo & $43,95 \mathrm{a}$ & $47,92 \mathrm{a}$ & $49,33 a$ & $44,04 \mathrm{a}$ & $41,46 \mathrm{Ba}$ & 45,34 \\
\hline $0,5 \%$ cal & $38,67 \mathrm{~b}$ & $42,00 \mathrm{ab}$ & $51,10 \mathrm{ab}$ & $47,68 \mathrm{ab}$ & $53,80 \mathrm{ABa}$ & 46,65 \\
\hline L. buchneri & $39,79 \mathrm{~b}$ & $49,78 \mathrm{ab}$ & $53,74 \mathrm{a}$ & $54,22 \mathrm{a}$ & $55,05 \mathrm{Aa}$ & 50,51 \\
\hline \multirow[t]{2}{*}{ Média } & 40,80 & 46,56 & 51,39 & 48,65 & 50,10 & \\
\hline & \multicolumn{6}{|c|}{ Lignina $(\% \mathrm{MS})$} \\
\hline Sem aditivo & $7,25 \mathrm{ab}$ & $8,37 \mathrm{a}$ & $8,23 \mathrm{a}$ & $6,92 \mathrm{Bab}$ & $5,94 \mathrm{Bb}$ & 7,34 \\
\hline $0,5 \%$ cal & $6,88 \mathrm{a}$ & $7,73 \mathrm{a}$ & $7,90 \mathrm{a}$ & $8,11 \mathrm{ABa}$ & $8,16 \mathrm{ABa}$ & 7,75 \\
\hline L. buchneri & $6,69 \mathrm{~b}$ & $8,49 \mathrm{ab}$ & $8,23 \mathrm{ab}$ & 9,17Aa & $9,31 \mathrm{Aa}$ & 8,37 \\
\hline \multirow[t]{2}{*}{ Média } & 6,94 & 8,19 & 8,12 & 8,06 & 7,80 & \\
\hline & \multicolumn{6}{|c|}{ Carboidratos não fibrosos (\% MS) } \\
\hline Sem aditivo & $37,58 \mathrm{Ba}$ & $28,20 b$ & $24,52 b$ & $19,58 \mathrm{c}$ & $19,60 \mathrm{c}$ & 25,89 \\
\hline $0,5 \%$ cal & $38,97 \mathrm{ABa}$ & $28,58 \mathrm{~b}$ & $25,15 b$ & $21,09 \mathrm{c}$ & $17,43 \mathrm{c}$ & 26,24 \\
\hline L. buchneri & $41,59 \mathrm{Aa}$ & $25,17 \mathrm{~b}$ & $25,80 \mathrm{~b}$ & $20,18 \mathrm{c}$ & $17,98 \mathrm{c}$ & 26,14 \\
\hline \multirow[t]{2}{*}{ Média } & 39,38 & 27,31 & 25,15 & 20,28 & 18,34 & \\
\hline & \multicolumn{6}{|c|}{ Digestibilidade in vitro ( $\% \mathrm{MS})$} \\
\hline Sem aditivo & 63,93 & 59,72 & 57,57 & 54,53 & 55,45 & 58,24 \\
\hline $0,5 \%$ cal & 64,31 & 57,89 & 56,70 & 55,73 & 53,53 & 57,63 \\
\hline L. buchneri & 67,21 & 58,37 & 58,03 & 54,42 & 54,85 & 58,57 \\
\hline \multirow[t]{2}{*}{ Média } & $65,15 \mathrm{a}$ & $58,66 \mathrm{~b}$ & $57,43 \mathrm{~b}$ & $54,89 \mathrm{c}$ & $54,61 \mathrm{c}$ & \\
\hline & \multicolumn{6}{|c|}{ Digestibilidade verdadeira in vitro (\% MS) } \\
\hline Sem aditivo & 66,50 & 62,11 & 58,77 & 58,32 & 59,44 & $61,02 b$ \\
\hline $0,5 \%$ cal & 71,06 & 65,63 & 64,72 & 63,32 & 62,21 & $65,38 \mathrm{a}$ \\
\hline L. buchneri & 68,71 & 60,87 & 60,69 & 57,35 & 58,61 & $61,24 b$ \\
\hline Média & $68,75 \mathrm{a}$ & $62,87 \mathrm{~b}$ & $61,39 b c$ & $59,66 \mathrm{c}$ & $60,09 \mathrm{c}$ & \\
\hline
\end{tabular}

${ }^{(1)}$ Médias seguidas por letras iguais, maiúsculas nas colunas e minúsculas nas linhas, não diferem entre si pelo teste de Tukey, a 5\% de probabilidade. 
do silo, e com os maiores teores de FDN na silagem com inoculação, no momento da abertura dos silos.

$\mathrm{O}$ consumo de matéria seca $\left(\mathrm{g} \mathrm{kg}^{-1}\right.$ de $\left.\mathrm{PV}^{0,75}\right)$ da silagem com inoculante foi inferior ao consumo da silagem com cal virgem ou da cana-de-açúcar in natura (Tabela 5). Segundo McDonald et al. (1991), a alta concentração de ácido acético em silagens pode reduzir o consumo voluntário de MS. Embora não tenham sido realizadas análises de ácidos orgânicos, a menor perda por efluente e o maior teor de carboidratos solúveis na silagem com inoculante podem ter resultado em maior concentração de ácido acético. Considerando que não houve efeito da adição de L. buchneri sobre a perda de MS e que a produção de gás de MS foi de 9,16 e 7,82\% nas silagens com cal e L. buchneri, respectivamente, é possível que tenha ocorrido produção de etanol na silagem com inoculante, o que teria prejudicado o consumo de MS. Segundo Nussio \& Schmidt (2005), o acúmulo de etanol pode não somente representar perdas do material ensilado, mas também perdas decorrentes da recusa dos animais. Além disso, o menor consumo da silagem com inoculante pode ser atribuído ao maior teor de FDN e à menor DIVMS verdadeira, em comparação com a silagem com cal, uma vez que a FDN é consistentemente associada ao consumo voluntário de MS (Van Soest, 1978). Kozloski et al. (2006) e Cardoso et al. (2006) verificaram que o consumo de MS de cordeiros diminui linearmente com o aumento do teor de FDN. Mendes et al. (2008), ao utilizar 50\% de concentrado na dieta, não observaram diferença significativa entre o consumo de MS da cana-de-açúcar in natura e da silagem de cana-de-açúcar contendo
L. buchneri, embora os teores de FDN das dietas tenham sido 35 e $45 \%$, respectivamente. Os consumos de MS de cana-de-açúcar in natura e de silagem de cana-deaçúcar contendo L. buchneri observados por Mendes et al. (2008) foram duas vezes maiores que os valores observados neste trabalho (Tabela 5), possivelmente pela quantidade de concentrado naquela dieta.

Os resultados da digestibilidade da MS in vitro (DIVMS) não condizem com os obtidos in vivo (DIGMS). A DIGMS da cana-de-açúcar ensilada com inoculante microbiano não se alterou, mas diminuiu na silagem tratada com cal virgem (Tabela 5). Schmidt et al. (2007) não observaram alteração na digestibilidade aparente da MS de rações experimentais contendo silagens de cana-de-açúcar, com inoculante com L. buchneri ou sem inoculante, e o coeficiente de digestibilidade foi maior que o encontrado no presente trabalho, uma vez que a ração continha $35 \%$ de concentrado. A menor DIGMS da silagem com cal virgem deve-se à maior produção de efluentes com carboidratos solúveis e, possivelmente, produtos da hidrólise. A redução da DIGMS da silagem com cal virgem, quando comparada com a da silagem com inoculante, demonstra maior importância em conter perdas de componentes solúveis que em hidrolisar a fibra.

A diferença entre resultados de digestibilidade in vitro e in vivo deve-se à taxa de passagem do alimento pelo sistema digestivo do animal. Isso indica necessidade de cautela na interpretação do resultado químico-bromatológico, uma vez que a velocidade de trânsito do bolo alimentar pelo sistema digestivo é

Tabela 5. Consumo e digestibilidade aparente da matéria seca (DIGMS), da proteína bruta (DIGPB), do extrato etéreo (DIGEE), da fibra insolúvel em detergente neutro (DIGFDN), da hemicelulose (DIGHEM), da fibra insolúvel em detergente ácido (DIGFDA), dos carboidratos totais (DIGCHOT), dos carboidratos não fibrosos (DIGCNF) e dos nutrientes digestíveis totais (NDT) da cana-de-açúcar in natura e ensilada com Lactobacillus buchneri ou cal virgem ${ }^{(1)}$.

\begin{tabular}{|c|c|c|c|c|}
\hline Variável & Cana-de-açúcar in natura & Silagem com óxido de cálcio & Silagem com L. buchneri & $\mathrm{EP}^{(2)}$ \\
\hline Consumo $\left(\mathrm{kg} \mathrm{dia}^{-1}\right)$ & 0,657 & 0,720 & 0,606 & 0,17 \\
\hline Consumo ( $\%$ do PV) & 1,60 & 1,61 & 1,16 & 0,31 \\
\hline Consumo $\left(\mathrm{g} \mathrm{kg}^{-1}\right.$ de PV) & 16,07 & 16,17 & 11,61 & 3,14 \\
\hline Consumo $\left(\mathrm{g} \mathrm{kg}^{-1}\right.$ de $\left.\mathrm{PV}^{(0,75)}\right)$ & $42,00 \mathrm{a}$ & $41,74 \mathrm{a}$ & $29,89 b$ & 7,75 \\
\hline DIGMS & $60,66 a$ & $51,98 \mathrm{~b}$ & $59,07 \mathrm{a}$ & 3,25 \\
\hline DIGPB & $59,47 \mathrm{~b}$ & $59,35 b$ & $66,88 \mathrm{a}$ & 3,92 \\
\hline DIGEE & $40,15 b$ & $63,40 \mathrm{a}$ & $55,50 \mathrm{ab}$ & 10,40 \\
\hline DIGFDN & 36,59 & 37,71 & 35,56 & 10,00 \\
\hline DIGHEM & 55,61 & 41,33 & 54,13 & 18,92 \\
\hline DIGFDA & 24,03 & 35,62 & 25,02 & 13,72 \\
\hline DIGCHOT & $61,52 \mathrm{a}$ & $54,70 \mathrm{~b}$ & $58,95 \mathrm{ab}$ & 3,92 \\
\hline DIGCNF & $97,16 \mathrm{a}$ & $85,84 \mathrm{~b}$ & $84,30 \mathrm{~b}$ & 8,23 \\
\hline NDT & $61,23 \mathrm{a}$ & $51,70 \mathrm{~b}$ & $54,14 \mathrm{ab}$ & 5,73 \\
\hline
\end{tabular}

${ }^{(1)}$ Médias seguidas por letras iguais nas linhas não diferem entre si pelo teste de Tukey, a 5\% de probabilidade. (2)Erro-padrão da média. 
maior que o tempo de incubação da amostra em tubo de ensaio, o que aumenta a degradação dos nutrientes. Os resultados demonstram que a hidrólise da FDN, provocada pela cal virgem e detectada pela análise laboratorial, ocorreu em uma fração potencialmente digestível, e que a velocidade de trânsito desse volumoso pelo sistema digestivo do animal permitiu semelhante aproveitamento dessa fração fibrosa em silagem contendo inoculante microbiano. Além disso, o maior consumo da silagem com cal virgem, quando comparado ao da silagem com inoculante microbiano, pode ocasionar aumento na velocidade de passagem e reduzir a DIGMS.

DIGFDN, DIGFDA e DIGHEM não apresentaram diferença entre os tratamentos (Tabela 5). Schmidt et al. (2007) não observaram alteração entre a digestibilidade da FDN ou FDA de silagens com inoculante contendo L. buchneri quando comparada à da silagem sem aditivo. A ausência de efeito na DIGFDA e DIGFDN condiz com a ausência de efeito nos teores de FDA e diverge da redução no teor de FDN da silagem com cal virgem no momento da abertura. A exemplo do efeito na DIGMS, o resultado demonstra que a fração da FDN hidrolisada pela cal virgem é potencialmente digestível e, portanto, a taxa de passagem do volumoso permite que a fração hidrolisada seja digerida in vivo, mesmo sem o tratamento. Schmidt et al. (2007) também observaram resultados conflitantes entre coeficiente de digestibilidade in vitro e in vivo em silagens de cana-de-açúcar, e atribuíram esse resultado à taxa de passagem de sólidos pelo trato digestivo do animal. A FDN hidrolisada pela cal virgem pode resultar em constituintes que deixam de compor a FDN e, portanto, a FDN residual após a ensilagem seria menos digerida, uma vez que sua fração mais facilmente degradável já teria sido solubilizada, o que resultaria em menores coeficientes de DIGHEM.

A DIGPB da silagem de cana-de-açúcar com inoculante foi superior à da silagem com cal virgem ou à da cana-de-açúcar in natura (Tabela 5). Enquanto a cal virgem elimina microrganismos indiscriminadamente, as bactérias L. buchneri têm função inibidora sobre leveduras e fungos, espécies de microrganismos deterioradores (Driehuis et al., 1999; Elferink et al., 2001), e seleciona microrganismos cuja proliferação resulta em proteína microbiana na silagem, o que aumenta a DIGPB.

ADIGEE foimaior na silagem com cal virgem quando comparada à cana-de-açúcar in natura (Tabela 5).
Possivelmente, a utilização da cal virgem resultou na formação de complexos entre ácidos graxos e cálcio, o que teria protegido os ácidos graxos da biohidrogenação no rúmen e tornado esses nutrientes mais solúveis que os ácidos graxos que sofreram bio-hidrogenação. A saturação completa dos ácidos graxos pela hidrogenação diminui drasticamente sua digestibilidade, enquanto ácidos graxos resistentes a bio-hidrogenação ruminal têm alto grau de eficiência de aproveitamento no intestino (Lucci, 1997). Os ácidos graxos de cadeia longa unem-se aos sais biliares e formam micelas que são absorvidas pela célula da mucosa no intestino delgado (Lehninger et al., 1992). Lipídios altamente hidrogenados não se incorporam suficientemente às micelas formadas por sais biliares e ácidos graxos, o que é essencial para a sua absorção. De acordo com Davis (1993), o tamanho da partícula de lipídio hidrogenado pode dificultar a dispersão dos ácidos graxos no quimo e resultar em baixa digestibilidade. Por outro lado, com a contribuição de lipases da planta e bacterianas (Demeyer \& Van Nevel, 1995) no silo, ésteres de glicerol de ácidos graxos de cadeia longa são liberados por processos hidrolíticos, o que resulta em ácidos graxos livres, aptos para a ligação com o cálcio da cal virgem. Sukhija \& Palmquist (1990) relataram que sais de cálcio de ácidos graxos poliinsaturados dissociam-se em maiores quantidades que os ácidos saturados em menores valores de $\mathrm{pH}$. Dessa forma, o $\mathrm{pH}$ mais baixo no duodeno e a ação de enzimas resultam em maior dissociação dos sais de cálcio de ácidos graxos que de ácidos graxos que sofreram bio-hidrogenação, e aumenta a digestibilidade intestinal e a DIGEE da silagem com cal virgem. Esse resultado demonstra o potencial da cal virgem em proteger ácidos graxos insaturados da bio-hidrogenação e aumentar a DIGEE.

A DIGCHOT foi maior $(p=0,054)$ na cana-de-açúcar in natura, quando comparada à da silagem tratada com cal virgem, e não houve diferença em relação à da silagem contendo inoculante microbiano (Tabela 5). Esse fato demonstra a maior importância da preservação de carboidratos não estruturais pelo inoculante microbiano em relação à hidrólise de carboidratos estruturais pela ação da cal virgem. Não houve diferença da DIGCNF entre as silagens contendo inoculante microbiano ou cal virgem, mas ambas apresentaram menores valores $(\mathrm{p}=0,058)$, quando comparadas à cana-de-açúcar in natura (Tabela 5). 
O NDT da cana-de-açúcar in natura foi superior $(p=0,055)$ ao da silagem com cal virgem, sem haver diferença entre as silagens (Tabela 5). Considerada uma produção agronômica hipotética de $100 \mathrm{Mg} \mathrm{ha}^{-1} \mathrm{de}$ massa de matéria verde, com $27 \%$ de MS, e associados os valores de NDT com as perdas de MS, foi observado que a energia digestível produzida (NDT ha ${ }^{-1}$ ) foi de $16,5,11,18$ e $11,17 \%$ para cana-de-açúcar in natura, silagem tratada com cal virgem e silagem com L. buchneri, respectivamente.

\section{Conclusões}

1. Independentemente do aditivo usado, a ensilagem reduz a produção de energia digestível e, consequentemente, aumenta o custo por unidade de energia digestível produzida.

2. A cal virgem e o Lactobacillus buchneri não são eficientes em conter perdas de matéria seca na ensilagem da cana-de-açúcar, mas, após a abertura do silo, são eficientes em conter perdas de matéria seca e em aumentar a estabilidade aeróbia da silagem.

3. A redução no teor de fibra insolúvel em detergente neutro (FDN) da cana-de-açúcar, pela ação da cal virgem, ocorre na fração potencialmente digestível e não tem efeito sobre a digestibilidade in vivo da FDN.

4. A utilização de cal virgem aumenta a digestibilidade aparente do extrato etéreo.

\section{Referências}

BALIEIRO NETO, G.; SIQUEIRA, G.R.; NOGUEIRA, J.R.; REIS, R.A.; ROTH, M. de T.P.; ROTH, A.P. de T.P. Perdas fermentativas e estabilidade aeróbia de silagens de cana-de-açúcar aditivadas com cal virgem. Revista Brasileira de Saúde e Produção Animal, v.10, p.24-33, 2009.

BALIEIRO NETO, G.; SIQUEIRA, G.R.; REIS, R.A.; NOGUEIRA, J.R.; ROTH, M. de T.P.; ROTH, A.P. de T.P. Óxido de cálcio como aditivo na ensilagem de cana-de-açúcar. Revista Brasileira de Zootecnia, v.36, p.1231-1239, 2007.

BERNARDES, T.F.; REIS, R.A.; SIQUEIRA, G.R.; AMARAL, R.C. do; PIRES, A.J.V. Estabilidade aeróbia da ração total e de silagens de capim-marandu tratadas com aditivos químicos e bacterianos. Revista Brasileira de Zootecnia, v.36, p.754-762, 2007.

CARDOSO, A.R.; PIRES, C.C.; CARVALHO, S.; GALVANI, D.B.; JOCHIMS, F.; HASTENPFLUG, M.; WOMMER, T.P. Consumo de nutrientes e desempenho de cordeiros alimentados com dietas que contêm diferentes níveis de fibra em detergente neutro. Ciência Rural, v.36, p.215-221, 2006.

DAVIS, C.L. Grasas en la racion. In: DAVIS, C.L. Alimentación de la vaca lechera alta productora. Illinois: Milk Specialties Company, 1993. p.26-30.
DEMEYER, D.I.; VAN NEVEL, C.J. Transformations and effects of lipids in the rumen: three decades of research at Gent University. Archives of Animal Nutrition, v.48, p.119-134, 1995.

DRIEHUIS, F.; ELFERINK, S.J.W.H.O; SPOELSTRA, S.F. Anaerobic lactic acid degradation during ensilage of whole crop maize inoculated with Lactobacillus buchneri inhibits yeast growth and improves aerobic stability. Journal of Applied Microbiology, v.87, p.583-594, 1999.

ELFERINK， S.J.W.H.O.; KROONEMAN，J.; GOTTSCHAL, J.C.; SPOELSTRA, S.F.; FABER, F.; DRIEHUIS, F. Anaerobic conversion of lactic acid to acetic acid and 1,2-propanediol by Lactobacillus buchneri. Applied and Environmental Microbiology, v.67, p.125-132, 2001.

FREITAS, A.W. de P.; PEREIRA, J.C.; ROCHA, F.C.; COSTA, M.G.; LEONEL, F. de P.; RIBEIRO, M.D. Avaliação da qualidade nutricional da silagem de cana-de-açúcar com aditivos microbianos e enriquecida com resíduo da colheita de soja. Revista Brasileira de Zootecnia, v.35, p.38-47, 2006.

HILL, J.; LEAVER, J.D. Changes in chemical composition and nutritive value of urea treated whole crop wheat during exposure to air. Animal Feed Science and Technology, v.102, p.181-195, 2002.

JACKSON, M.G. Review article: the alkali treatment of straws. Animal Feed Science and Technology, v.2, p.105-130, 1977.

JOBIM, C.C.; NUSSIO, L.G.; REIS, R.A.; SCHMIDT, P. Avanços metodológicos na avaliação da qualidade da forragem conservada. Revista Brasileira de Zootecnia, v.36, p.101-119, 2007.

KOZLOSKI, G.V.; TREVISAN, L.M.; BONNECARRÈRE, L.M.; HÄRTER, C.J.; FIORENTINI, G.; GALVANI, D.B.; PIRES, C.C. Níveis de fibra em detergente neutro na dieta de cordeiros: consumo, digestibilidade e fermentação ruminal. Arquivo Brasileiro de Medicina Veterinária e Zootecnia, v.58, p.893-900, 2006.

KUNG JUNIOR, L.; GRIEVE, D.B.; THOMAS, J.W.; HUBER, J.T. Added ammonia or microbial inocula for fermentation and nitrogenous compounds of alfalfa ensiled at various percents of dry matter. Journal of Dairy Science, v.67, p.299-306, 1984.

KUNG JUNIOR, L.; STANLEY, R.W. Effect of stage of maturity on the nutritive value of whole-plant sugarcane preserved as silage. Journal of Animal Science, v.54, p.689-696, 1982.

LEHNINGER, A.L.; NELSON, D.L.; COX, M.M. Lipídios. In: LEHNINGER, A.L.; NELSON, D.L.; COX, M.M. Princípios de bioquímica. São Paulo: Sarvier, 1992. p.179-198.

LEIBENSPERGER, P.Y; PITT, R.E. A model of clostridial dominance in silage. Grass and Forrage Science, v.42, p.297-317, 1987.

LUCCI, C. de S. Nutrição e manejo de bovinos leiteiros. São Paulo: Manole, 1997. 169p.

MAGALHÃES, A.L.R.; CAMPOS, J.M. de S.; VALADARES FILHO, S. de C.; TORRES, R. de A.; MENDES NETO, J.; ASSIS, A.J. de. Cana-de-açúcar em substituição à silagem de milho em dietas para vacas em lactação: desempenho e viabilidade econômica. Revista Brasileira de Zootecnia, v.33, p.1292-1302, 2004.

MCDONALD, P.; HENDERSON, A.R.; HERON, S.J.E. The biochemistry of silage. 2.ed. Marlow: Chalcombe Publications, 1991. 340p. 
MENDES, C.Q.; SUSIN, I.; PIRES, A.V.; NUSSIO, L.G.; ARAUJO, R.C.; RIBEIRO, M.F. Desempenho, parâmetros da carcaça e comportamento ingestivo de cordeiros alimentados com cana-de-açúcar ensilada ou in natura. Arquivo Brasileiro de Medicina Veterinária e Zootecnia, v.60, p.733-740, 2008.

NATIONAL RESEARCH COUNCIL. Nutrient requirements of dairy cattle. $7^{\text {th }}$ ed. Washington: National Academy Press, 2001. $381 \mathrm{p}$.

NATIONAL RESEARCH COUNCIL. Nutrient requirements of sheep. $6^{\text {th }}$ ed. Washington: National Academy of Science, 1985. 99p.

NUSSIO, L.G.; SCHMIDT, P. Silagens de cana-de-açúcar para bovinos leiteiros: aspectos agronômicos e nutricionais. In: SIMPÓSIO SOBRE BOVINOCULTURA LEITEIRA, 5., 2005, Piracicaba. Visão técnica e econômica da produção leiteira: anais. Piracicaba: Fundação de Estudos Agrários Luiz de Queiroz, 2005. p.193-218.

NUSSIO, L.G.; SCHMIDT, P.; PEDROSO, A.F. Silagem de cana-de-açúcar. In: EVANGEISTA, A.R.; REIS, S.T.; GOMIDE, E.M. (Ed.). Forragicultura e pastagens: temas em evidência: sustentabilidade. Lavras: Ufla, 2003. p.49-72.

O'KIELY, P.; MOLONEY, A.; KEATING, T.; SHIELS, P. Maximising output of beef within cost efficient, environmentally compatible forage conservation systems. Dunsany: Grange Research Centre, 1999. 64p. (Beef Productions Series, 10).

PAHLOW, G.; MUCK, R.E.; DRIEHUIS, F.; ELFERINK, S.J.W.H.O.; SPOELSTRA, S.F. Microbiology of ensiling. In: BUXTON, D.R.; MUCK, R.E.; HARRISON, J.H. (Ed.). Silage science and technology. Madison: American Society of Agronomy, 2003. p.31-93.

PEDROSO, A. de F.; NUSSIO, L.G.; LOURES, D.R.S.; PAZIANI, S. de F.; IGARASI, M.S.; COELHO, R.M.; HORII, J.; ANDRADE, A. de A. Efeito do tratamento com aditivos químicos e inoculantes bacterianos nas perdas e na qualidade de silagens de cana-deaçúcar. Revista Brasileira de Zootecnia, v.36, p.558-564, 2007.

PEDROSO, A.D.; NUSSIO, L.G.; PAZIANI, S.D.F.; LOURES, D.R.S.; IGARASI, M.S.; COELHO, R.M.; PACKER, I.H.; HORII, J.; GOMES, L.H. Fermentation and epiphytic microflora dynamics in sugar cane silage. Scientia Agricola, v.62, p.427-432, 2005.

PRESTON, T.R.; HINOJOSA, C.; MARTINEZ, L. Ensiling of sugar cane with ammonia molasses and mineral acids. Tropical Animal Production, v.1, p.120-126, 1976.
QUEIROZ, O.C.M.; NUSSIO, L.G.; SCHMIDT, P.; RIBEIRO, J.L.; SANTOS, M.C.; ZOPOLLATTO, M. Silagem de canade-açúcar comparada a fontes tradicionais de volumosos suplementares no desempenho de vacas de alta produção. Revista Brasileira de Zootecnia, v.37, p.358-365, 2008.

RUPPEL, K.A.; PITT, R.E.; CHASE, L.E.; GALTON, D.M. Bunker silo management and its relationship to forage preservation on dairy farms. Journal of Dairy Science, v.78, p.141-153, 1995.

SANTOS, M.C.; NUSSIO, L.G.; MOURÃO, G.B.; SCHMIDT, P.; MARI, L.J.; RIBEIRO, J.L.; QUEIROZ, O.C.M.; ZOPOLLATTO, M.; SOUSA, D. de P.; SARTURI, J.O.; TOLEDO FILHO, S.G. de. Nutritive value of sugarcane silage treated with chemical additives. Scientia Agricola, v.66, p.159-163, 2009.

SAS INSTITUTE. SAS user's guide: statistics. Version 9.1. Cary: SAS Institute, 2003.

SCHMIDT, P.; MARI, L.J.; NUSSIO, L.G.; PEDROSO, A. de F.; PAZIANI, S. de F.; WECHSLER, F.S. Aditivos químicos e biológicos na ensilagem de cana-de-açúcar. 1. Composição química das silagens, ingestão, digestibilidade e comportamento ingestivo. Revista Brasileira de Zootecnia, v.36, p.1666-1675, 2007.

SILVA, D.J.; QUEIROZ, A.C. Análise de alimentos: métodos químicos e biológicos. Viçosa: Universidade Federal de Viçosa, 2002. 235p.

SUKHIJA, P.S.; PALMQUIST, D.L. Dissociation of calcium soaps of long-chain fatty acids in rumen fluid. Journal of Dairy Science, v.73, p.1784-1787, 1990.

VAN SOEST, P.J. Nutritional ecology of the ruminant. $2^{\text {nd }} \mathrm{ed}$. New York: Cornell University Press, 1994. 476p.

VAN SOEST, P.J.; MERTENS, D.R.; DEINUM, B. Preharvest factors influencing quality of conserved forage. Journal of Animal Science, v.47, p.712-720, 1978.

VAN SOEST, P.J.; ROBERTSON, J.B.; LEWIS, B.A. Methods for dietary fiber, neutral detergent fiber, and nonstarch polysaccharides in relation to animal nutrition. Journal of Dairy Science, v.74, p.3583-3597, 1991.

WOOLFORD, M.K. The detrimental effects of air on silage. Journal of Applied Bacteriology, v.68, p.101-116, 1990.

WOOLFORD, M.K. The problem of silage effluent. Herbage abstracts, v.48, p.397-403, 1978.

Recebido em 16 de janeiro de 2009 e aprovado em 30 de abril de 2009 